Article

\title{
Gastroprotective and Healing Effects of Polygonum cuspidatum Root on Experimentally Induced Gastric Ulcers in Rats
}

\author{
Young-Sik Kim ${ }^{\circledR}$, YunSeol Nam, Jungbin Song * ${ }^{\mathbb{D}}$ and Hocheol Kim* \\ Department of Herbal Pharmacology, College of Korean Medicine, Kyung Hee University, 26 Kyungheedae-ro, \\ Dongdaemun-gu, Seoul 02447, Korea; yjbsik@gmail.com (Y.-S.K.); yunseol@naver.com (Y.N.) \\ * Correspondence: jbsong@khu.ac.kr (J.S.); hckim@khu.ac.kr (H.K.); \\ Tel.: +82-2-961-9394 (J.S.); +82-2-961-0419 (H.K.)
}

Received: 16 June 2020; Accepted: 23 July 2020; Published: 27 July 2020

check for updates

\begin{abstract}
Polygonum cuspidatum is widely used as food and medicine in Korea, China, and Japan. Its major bioactive components, resveratrol and emodin, reportedly protect against gastric lesions. We therefore aimed to investigate: (1) the gastroprotective effects of P. cuspidatum roots in hydrochloric acid/ethanol ( $\mathrm{HCl} / \mathrm{EtOH})$ - and indomethacin-induced acute gastric ulcer rat models; (2) the healing effects in an acetic acid-induced ulcer model; and (3) potential mechanisms by measuring gastric acid secretion-related parameters in a pyloric ligation-induced ulcer model, and by measuring antioxidant enzyme and prostaglandin $\mathrm{E}_{2}$ levels in the gastric tissue of $\mathrm{HCl} / \mathrm{EtOH}$-treated rats. Oral administration of P. cuspidatum extract (PCE) at doses of 100 and $300 \mathrm{mg} / \mathrm{kg}$ significantly decreased $\mathrm{HCl} / \mathrm{EtOH}$ - and indomethacin-induced gastric lesions. PCE at $300 \mathrm{mg} / \mathrm{kg}$ significantly reduced gastric lesions in acetic acid-induced ulcers. PCE increased superoxide dismutase (SOD) activity and glutathione (GSH) and prostaglandin $\mathrm{E}_{2}$ levels in gastric tissue, whereas it did not alter gastric acid secretion-related parameters. Our findings indicate that PCE has gastroprotective effects against $\mathrm{HCl} / \mathrm{EtOH}$ and non-steroidal anti-inflammatory drugs (NSAIDs) and promotes healing of acetic acid-induced ulcers. These gastric mucosal protection and ulcer healing effects are associated with antioxidant effects and the augmentation of prostaglandin $\mathrm{E}_{2}$ and suggest that $P$. cuspidatum might be a promising preventive and therapeutic agent for treating gastric ulcers.
\end{abstract}

Keywords: Polygonum cuspidatum; gastric ulcer; gastritis; gastric acid; antioxidant; prostaglandin $\mathrm{E}_{2}$

\section{Introduction}

Gastric ulcers result from damage to the mucosal lining of the stomach due to an increase in aggressive factors such as reactive oxygen species (ROS) and gastric acid, and a decrease in protective factors such as prostaglandins and mucus [1,2]. The most common symptom is upper abdominal pain, which occurs at night and is relieved by food intake [3]. Gastric ulcers are very painful and lower the quality of life of those who suffer from them [4]. Lack of proper gastric ulcer treatment can induce gastrointestinal bleeding, perforation, and gastric outlet obstruction [5]. In South Korea, about $10 \%$ of people have suffered from gastric ulcers [6]. Lifestyle habits, such as excessive alcohol intake or prolonged use of non-steroidal anti-inflammatory drugs (NSAIDs), are factors that cause gastritis and gastric ulcer [7]. Infection by the common bacteria Helicobacter pylori is another significant cause of gastric ulcers.

Gastric ulcers are characterized by chronicity due to repeated episodes of healing and re-exacerbation $[8,9]$. As this disease can persist for many years, a long-term management therapy for patients with a gastric ulcer is essential [10]. The primary treatment entails reducing the production of gastric acids with antacids, proton pump inhibitors, or $\mathrm{H}_{2}$ receptor antagonists [11]. In the case 
of a gastric ulcer associated with $H$. pylori, treatment consists of a combination of antibiotics and acid secretion inhibitors [12]. Despite good therapeutic efficacy, the long-term use of acid secretion inhibitors often causes side effects, such as osteoporosis and hypergastrinemia [13]. For these reasons, research into the development of gastroprotective agents that are safer for long-term use, and which protect the gastric mucosa without affecting acid secretion, have attracted interest. Natural products have long been known to be safe and effective in treating gastric ulcer [7].

Polygonum cuspidatum Sieb. et Zucc., commonly called Asian or Japanese knotweed, is an herbaceous perennial plant native to East Asia. The stem and root of this plant are widely used as food and medicine in Korea, China, and Japan $[14,15]$. In particular, the root of P. cuspidatum has long been used for the treatment of pain, inflammation, infection, skin burns, scalding, and jaundice [14,16,17]. The major active constituents are anthraquinones (emodin, physcion, anthraglycoside B, etc.) and stilbenes (polydatin, resveratrol, etc.), which are known to be responsible for the diverse pharmacological properties of P. cuspidatum [14,18-20].

Recently, resveratrol and emodin, the major bioactive components of P. cuspidatum, have been reported to protect against gastric lesions. Resveratrol shows gastroprotective, anti-inflammatory, and antioxidant effects on EtOH-induced gastritis in rats [21], and also showed gastroprotective and ulcer healing effects on acetic acid-induced gastric ulcer [22]. Emodin was shown to protected against gastric ulcers induced by cold restraint, alcohol, aspirin, and pyloric ligation by reducing gastric acid secretion and increasing mucin and prostaglandin $\mathrm{E}_{2}\left(\mathrm{PGE}_{2}\right)$ secretion [23]. These previous findings led us to hypothesize that P. cuspidatum may have gastroprotective and ulcer healing effects. This study therefore aimed to investigate these effects using P. cuspidatum extract (PCE), and to explore the underlying mechanisms of these effects using different gastric ulcer rat models. Gastric ulcers were induced by hydrochloric acid/ethanol $(\mathrm{HCl} / \mathrm{EtOH})$, indomethacin, and acetic acid; lesion areas were then measured. To determine the effect of P. cuspidatum on the aggressive and protective factors that are involved in gastric ulcer, we measured gastric secretion parameters in pylorus-ligated rats and evaluated the levels of antioxidant factors and $\mathrm{PGE}_{2}$ in the gastric tissues of $\mathrm{HCl} / \mathrm{EtOH}$-treated rats.

\section{Materials and Methods}

\subsection{Plant Materials and Sample Preparation}

Dried P. cuspidatum roots were obtained from Daewoo Medicinal Herbs Co. (Seoul, Korea). The plant materials were authenticated by professor Hocheol Kim of Kyung Hee University and extracted with 10 volumes of $30 \% \mathrm{EtOH}$ at $85{ }^{\circ} \mathrm{C}$ for $3 \mathrm{~h}$ in a reflux apparatus. The extract was concentrated in vacuo using a rotary evaporator (Eyela N-1000, Tokyo, Japan), and lyophilized in a freeze dryer (Operon OPR-FD4-8612, Gyeonggi-do, Korea). The final extract yield was 15.53\%. The extract was kept in the refrigerator at $4{ }^{\circ} \mathrm{C}$. The voucher plant material specimens were deposited in the Department of Herbal Pharmacology, College of Korean Medicine, Kyung Hee University.

\subsection{High-Performance Liquid Chromatography (HPLC) Analysis}

The contents of the marker compounds, polydatin and emodin, were quantified with HPLC on an Agilent 1220 HPLC system (Agilent Technology, Santa Clara, CA, USA) that was equipped with a G4281B binary pump, a G4282B autosampler, and a G4285B diode array detector using a Sunfire ${ }^{\mathrm{TM}}$ C18-column ( $5 \mu \mathrm{m} ; 250 \times 4.6 \mathrm{~mm}$; Waters, Milford, MA, USA). The mobile phase consisted of $0.1 \%(v / v)$ phosphoric acid in distilled water (A) and acetonitrile (B). The gradient elution conditions for detection were as follows: $0-60-65-67-72 \mathrm{~min}, 0-100-100-0-0 \%$ solvent $\mathrm{B}$. The flow rate was $1.0 \mathrm{~mL} / \mathrm{min}$. The detection wavelengths were set to $306 \mathrm{~nm}$ for polydatin and resveratrol and to $290 \mathrm{~nm}$ for emodin, according to the maximum absorption wavelength of each compound.

\subsection{Animals}

Six-week-old male Sprague-Dawley (SD) specific pathogen-free rats and seven-week old male Wistar rats (Samtako, Gyeonggi-do, Korea) were used after a 1-week acclimatization period. Rats were housed under standard laboratory conditions with $23 \pm 1{ }^{\circ} \mathrm{C}$ temperature, $55 \pm 5 \%$ relative humidity, 
and $12 \mathrm{~h} \mathrm{light/dark} \mathrm{cycle} \mathrm{and} \mathrm{allowed} \mathrm{free} \mathrm{access} \mathrm{to} \mathrm{food} \mathrm{and} \mathrm{water.} \mathrm{Rats} \mathrm{were} \mathrm{monitored} \mathrm{once} \mathrm{daily} \mathrm{for}$ health status during the acclimatization period; no abnormal findings were observed. All experimental procedures were approved by the Institutional Animal Care and Use Committee, Korea Institute of Science and Technology for Eastern Medicine (no. KISTEM-IACUC-2015-005) and Kyung Hee University Institutional Animal Care and Use Committee (no. KHUASP (SE)-17-081).

\subsection{HCl/EtOH-Induced Acute Gastric Lesions}

The $\mathrm{HCl} / \mathrm{EtOH}$-induced ulceration was conducted according to the protocol of Mizui and Doteuchi [24]. Thirty SD rats were randomly assigned to four groups: control $(n=8)$, omeprazole $20 \mathrm{mg} / \mathrm{kg}$ (positive control, $n=7)$, PCE $100 \mathrm{mg} / \mathrm{kg}(n=7)$, and PCE $300 \mathrm{mg} / \mathrm{kg}(n=8)$. After a $24 \mathrm{~h}$ fast, samples were administered by oral gavage at a volume of $10 \mathrm{~mL} / \mathrm{kg}$ body weight; the control group received the vehicle (distilled water) at the same volume. One hour after sample administration, $1.5 \mathrm{~mL}$ of $60 \% \mathrm{EtOH}$ in $150 \mathrm{mM} \mathrm{HCl}$ solution was administered by oral gavage for induction of gastric lesions. The rats were euthanized by cervical dislocation $1 \mathrm{~h}$ post-HCl/EtOH administration. The stomachs were quickly removed, incised along the greater curvature, and then washed with sterile saline. The stomachs were stretched on a flat plate and photographed to analyze the gastric lesions. The gastric samples were stored at $-80{ }^{\circ} \mathrm{C}$ until used for analysis of antioxidant enzyme activity and $\mathrm{PGE}_{2}$ concentration. The area of gastric lesion was measured using image J program (National Institutes of Health, Bethesda, Rockville, MD, USA). The gastric lesion index was calculated as follows:

$$
\text { Gastric lesion index }=\frac{\text { Gastric lesion area }\left(\mathrm{mm}^{2}\right)}{\text { Total gastric area }\left(\mathrm{mm}^{2}\right)} \times 100
$$

\subsection{Indomethacin-Induced Acute Gastric Lesions}

The effects of PCE on indomethacin-induced gastric lesions were assessed, and the gastroprotective effects of PCE were compared with those of omeprazole, a proton pump inhibitor. Twenty-eight SD rats were randomly assigned to four groups: control $(n=8)$, omeprazole $20 \mathrm{mg} / \mathrm{kg}(n=6)$, PCE $100 \mathrm{mg} / \mathrm{kg}$ $(n=7)$, and PCE $300 \mathrm{mg} / \mathrm{kg}(n=7)$. After a $24 \mathrm{~h}$ fast, samples were administered by oral gavage at a volume of $10 \mathrm{~mL} / \mathrm{kg}$ body weight; the control group received the vehicle (distilled water) at the same volume. Thirty minutes after sample administration, indomethacin in $5 \% \mathrm{NaHCO}_{3}$ solution was administered orally at a dose of $100 \mathrm{mg} / \mathrm{kg}$ for the induction of gastric lesions. The rats were euthanized by cervical dislocation $6 \mathrm{~h}$ post indomethacin administration. The stomachs were quickly removed, incised along the greater curvature, and then washed with sterile saline. The stomachs were stretched on a flat plate and photographed to analyze the gastric lesions. The area of gastric lesion was measured using image J program (National Institutes of Health, Bethesda, USA). The gastric lesion index was calculated as described above.

\subsection{Acetic Acid-Induced Chronic Gastric Lesions}

Chronic gastric lesions were induced as described by Okabe et al. [25]. After a $24 \mathrm{~h}$ fast, $28 \mathrm{Wistar}$ rats were anesthetized with $2 \%$ isoflurane in $70 \%$ nitrous oxide and $30 \%$ oxygen. After each abdomen was opened by small midline incision and the stomach was slightly lifted out, $500 \mu \mathrm{L}$ of $100 \%$ acetic acid was instilled into a $6 \mathrm{~mm}$ diameter plastic cylinder and allowed to remain on the serosa of the stomach for $1 \mathrm{~min}$. After aspiration of acetic acid, the serosa was washed with saline, the stomach was replaced carefully into the abdomen, and then the abdominal incision was closed. After surgical recovery, the 28 rats were randomly assigned to three groups: control $(n=10)$, omeprazole $20 \mathrm{mg} / \mathrm{kg}(n=10)$, and PCE $300 \mathrm{mg} / \mathrm{kg}(n=8)$. Beginning two days after ulcer induction, samples were administered by oral gavage at a volume of $10 \mathrm{~mL} / \mathrm{kg}$ body weight twice a day for a week, and the control group received the vehicle (distilled water) at the same volume. At the end of the treatment period, the rats were euthanized by cervical dislocation and the stomachs were quickly removed. The gastric ulcer lesion area and index were determined as described above. 


\subsection{Gastric Secretion in Pylorus-Ligated Rats}

The free and total acidity, volume, and $\mathrm{pH}$ of the gastric juice were determined using the method of Shay and Gruenstein [26]. Twenty-six SD rats were randomly assigned to four groups: control $(n=9)$, omeprazole $20 \mathrm{mg} / \mathrm{kg}(n=6)$, PCE $100 \mathrm{mg} / \mathrm{kg}(n=6)$, and PCE $300 \mathrm{mg} / \mathrm{kg}(n=5)$. After a $24 \mathrm{~h}$ fast, samples were administered by oral gavage at a volume of $10 \mathrm{~mL} / \mathrm{kg}$ body weight; the control group received the vehicle (distilled water) at the same volume. After $30 \mathrm{~min}$ of sample administration, rats were anesthetized with $2 \%$ isoflurane in $70 \%$ nitrous oxide and $30 \%$ oxygen. A $2 \mathrm{~cm}$ midline incision was made below the xiphoid process, and then the pyloric portion of the stomach was slightly lifted out and ligated avoiding bleeding or blood vessel occlusion. The stomach of each rat was placed carefully back into the abdomen and the wound was sutured. After $4 \mathrm{~h}$ of pylorus ligation, rats were euthanized by cervical dislocation and the stomach was removed. The gastric juice was collected and centrifuged at $3000 \mathrm{rpm}$ for $10 \mathrm{~min}$. The volume and $\mathrm{pH}$ of gastric juice were measured using a measuring cylinder and a $\mathrm{pH}$ meter (Ultrabasic benchtop meters, Denver Instrument, Denver, CO, USA). Free acidity was quantified by titration with $0.05 \mathrm{~N}$ sodium hydroxide using phenolphthalein as an indicator. Total acidity was calculated as follows:

Total Acidity $(m E q / 4 h r)=$ Vol. of gastric juice $(m L) \times$ Vol. of $\mathrm{NaOH}(m L) \times$ normality of $0.05 \mathrm{~N} \mathrm{NaOH}$

\subsection{Measurement of Superoxide Dismutase (SOD), Glutathione (GSH) Level, and Catalase (CAT) Activity}

The gastric antioxidant enzyme activity was measured in the $\mathrm{HCl} / \mathrm{EtOH}$-induced gastric ulcer model. Frozen stomach tissues were pulverized with liquid nitrogen using a mortar and pestle. The ground tissues (about $200 \mathrm{mg}$ ) were homogenized using a homogenizer (Bead Ruptor 24 Elite, OMNI International, Kennesaw, GA, USA) in $1 \mathrm{~mL}$ of $50 \mathrm{mM}$ sodium phosphate buffer (pH 7.0) containing $1 \mathrm{mM}$ ethylenediaminetetraacetic acid (EDTA). Homogenates were centrifuged at $4000 \mathrm{rpm}$ for $5 \mathrm{~min}$ at $4{ }^{\circ} \mathrm{C}$ and the supernatant was divided into two portions; one was used to measure SOD activity, and the other was centrifuged at $10,000 \mathrm{rpm}$ for $15 \mathrm{~min}$ at $4{ }^{\circ} \mathrm{C}$ in order to measure the CAT and GSH activities of the resultant supernatant. The activities of SOD, CAT, and GSH were determined using a SOD assay kit (catalog no. 706002, Cayman Chemical Company, Ann Arbor, MI, USA), a CAT assay kit (catalog no. 707002, Cayman Chemical Company, USA), and a GSH assay kit (catalog no. 703002, Cayman Chemical Company, USA), respectively, according to the manufacturers' protocols. The absorbance was measured at 450, 540, and $410 \mathrm{~nm}$, respectively, using a microplate spectrophotometer (Epoch 2, BioTek, Winooski, VT, USA). The antioxidant enzyme activity was normalized to the wet gastric tissue weight.

\subsection{Determination of $P G E_{2}$}

In order to evaluate the concentration of $\mathrm{PGE}_{2}$ in stomach tissue obtained from the $\mathrm{HCl} / \mathrm{EtOH}$-induced gastric ulcer model, about $200 \mathrm{mg}$ of stomach tissue was pulverized with liquid nitrogen using a mortar and pestle, then homogenized in $0.5 \mathrm{~mL}$ of $100 \mathrm{mM}$ phosphate buffer (pH 7.4) containing $1 \mathrm{mM}$ EDTA and $10 \mu \mathrm{M}$ indomethacin. Homogenized gastric samples were centrifuged at $8000 \mathrm{rpm}$ for $10 \mathrm{~min}$ at $4{ }^{\circ} \mathrm{C}$; the PGE 2 concentration in the supernatant was quantified using a PGE 2 express enzyme immunoassay kit (catalog no. 500141, Cayman Chemical Company, USA) according to the manufacturer's protocol. The absorbance was measured using a microplate reader (Epoch 2, BioTek, USA). The $\mathrm{PGE}_{2}$ concentrations were normalized to the wet gastric tissue weight, and the results are expressed as $\mathrm{pg} / \mathrm{mg}$ wet tissue.

\subsection{Statistical Analysis}

Values are presented as mean \pm the standard deviation. Statistical analysis was performed using GraphPad Prism 8 (GraphPad Software Inc., La Jolla, San Diego, CA, USA). Shapiro-Wilk test and Bartlett's test were used to determine normality and homoscedasticity, respectively. One-way 
analysis of variance (ANOVA) with Dunnett's test was used to analyze the normal, homoscedastic data. For heteroscedastic data, Welch's ANOVA with Dunnett's T3 multiple comparisons test or Kruskal-Wallis test with Dunn's multiple comparisons test (a non-parametric method) were used to test significance. $p<0.05$ was considered statistically significant.

\section{Results}

\subsection{HPLC Analysis of PCE}

Figure 1 shows the representative HPLC chromatograms of the standards mixture and PCE. The polydatin, resveratrol, and emodin contents were $8.66 \mathrm{mg} / \mathrm{g}, 2.90 \mathrm{mg} / \mathrm{g}$, and $3.95 \mathrm{mg} / \mathrm{g}$, respectively.

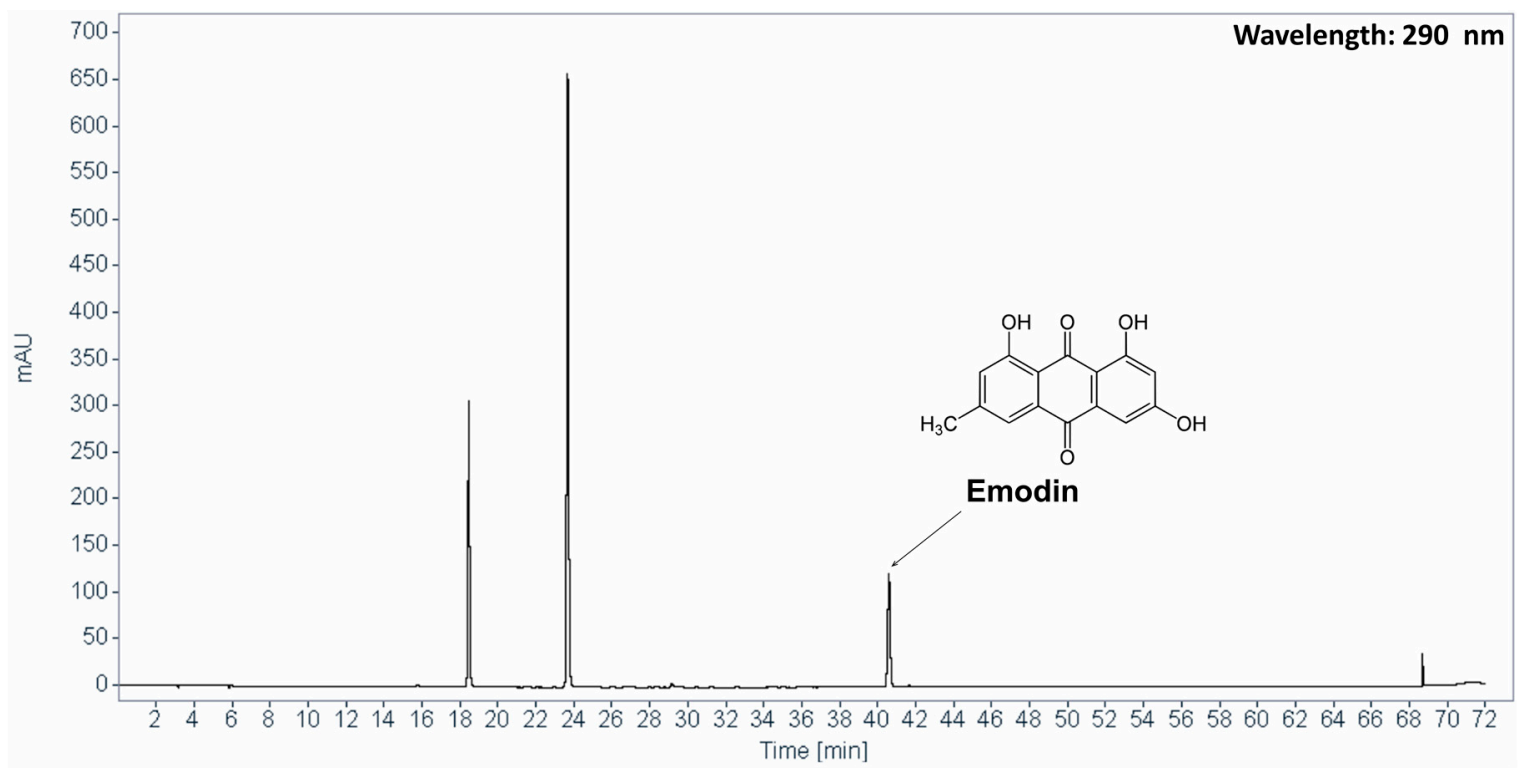

(a)

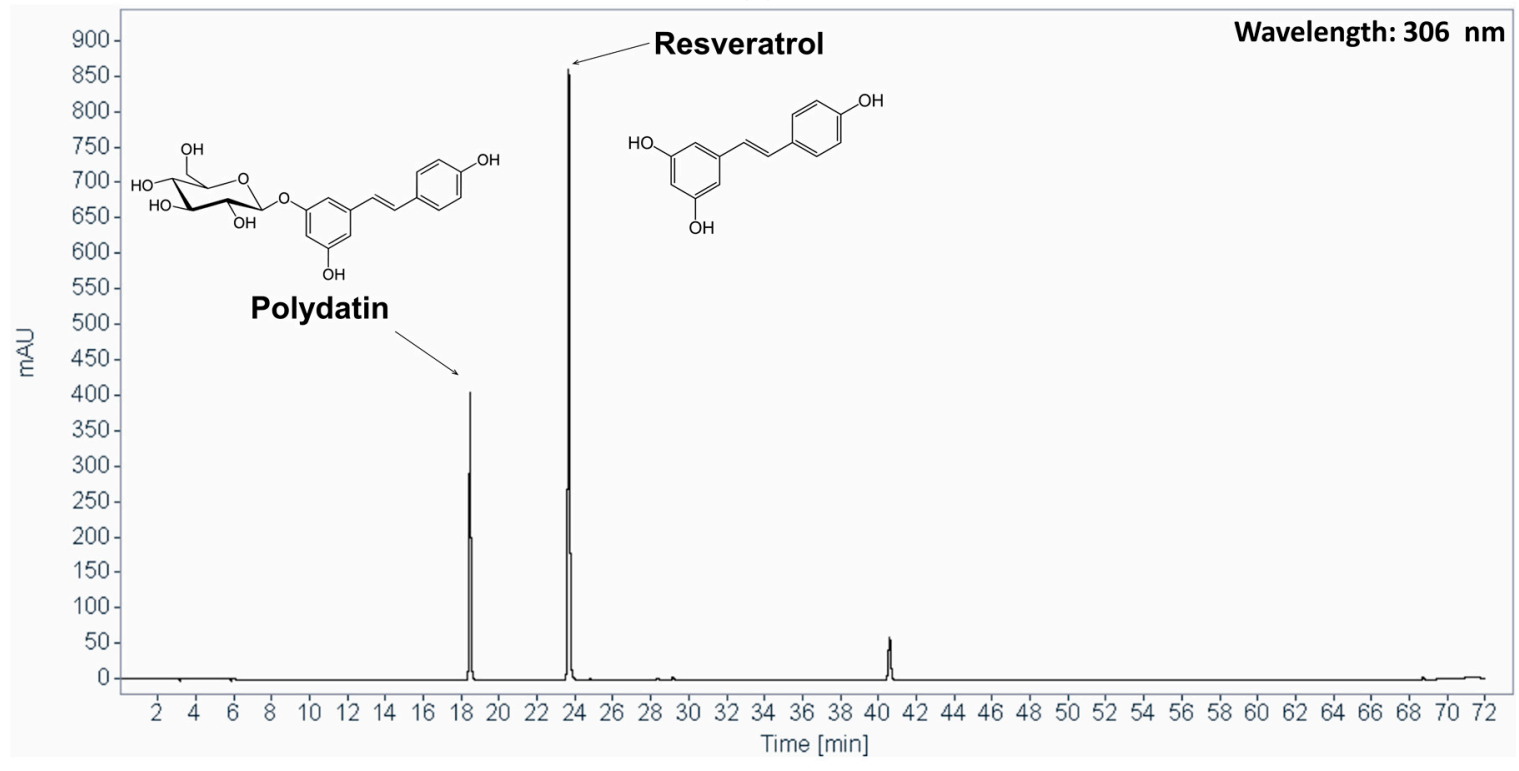

(b)

Figure 1. Cont. 


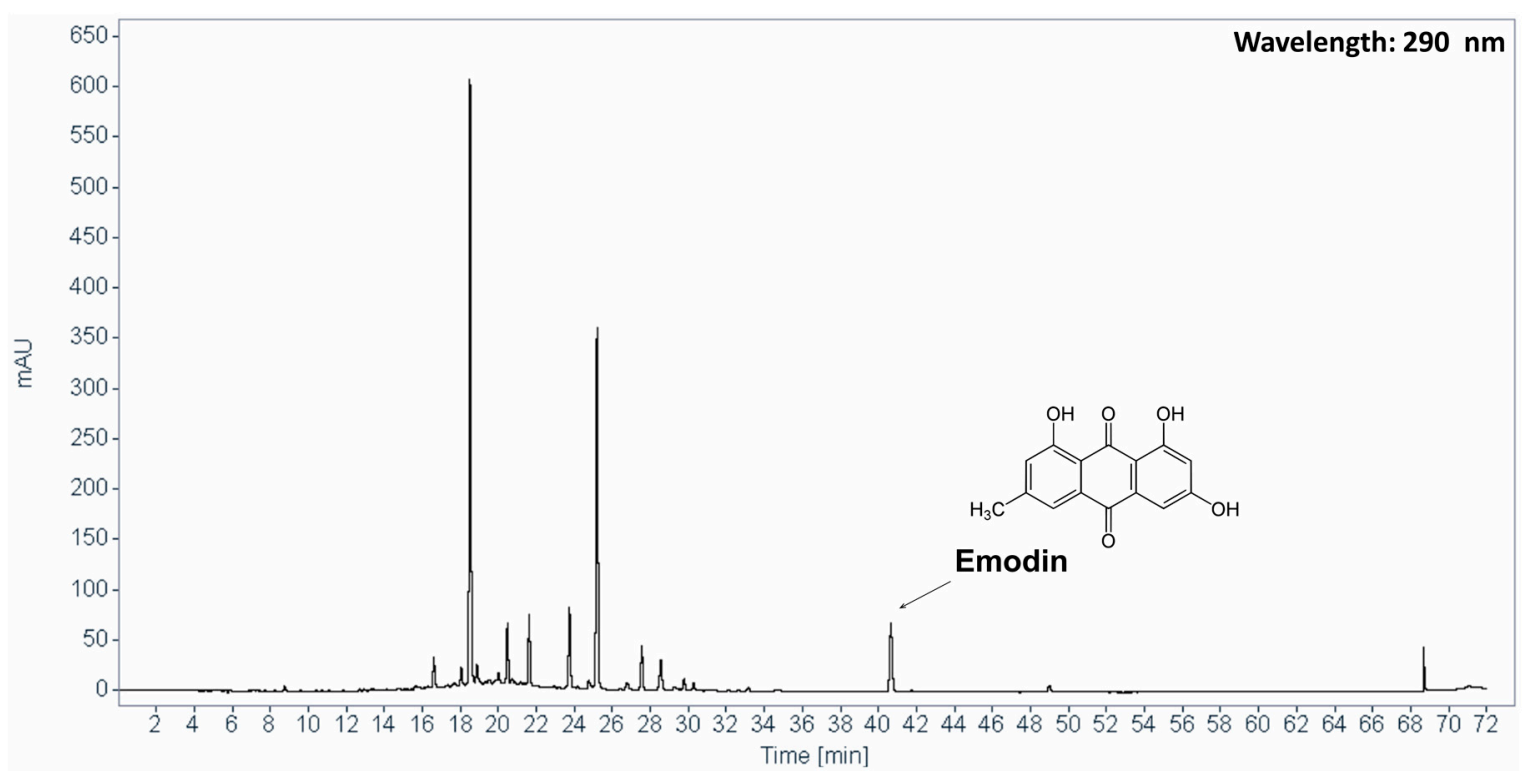

(c)

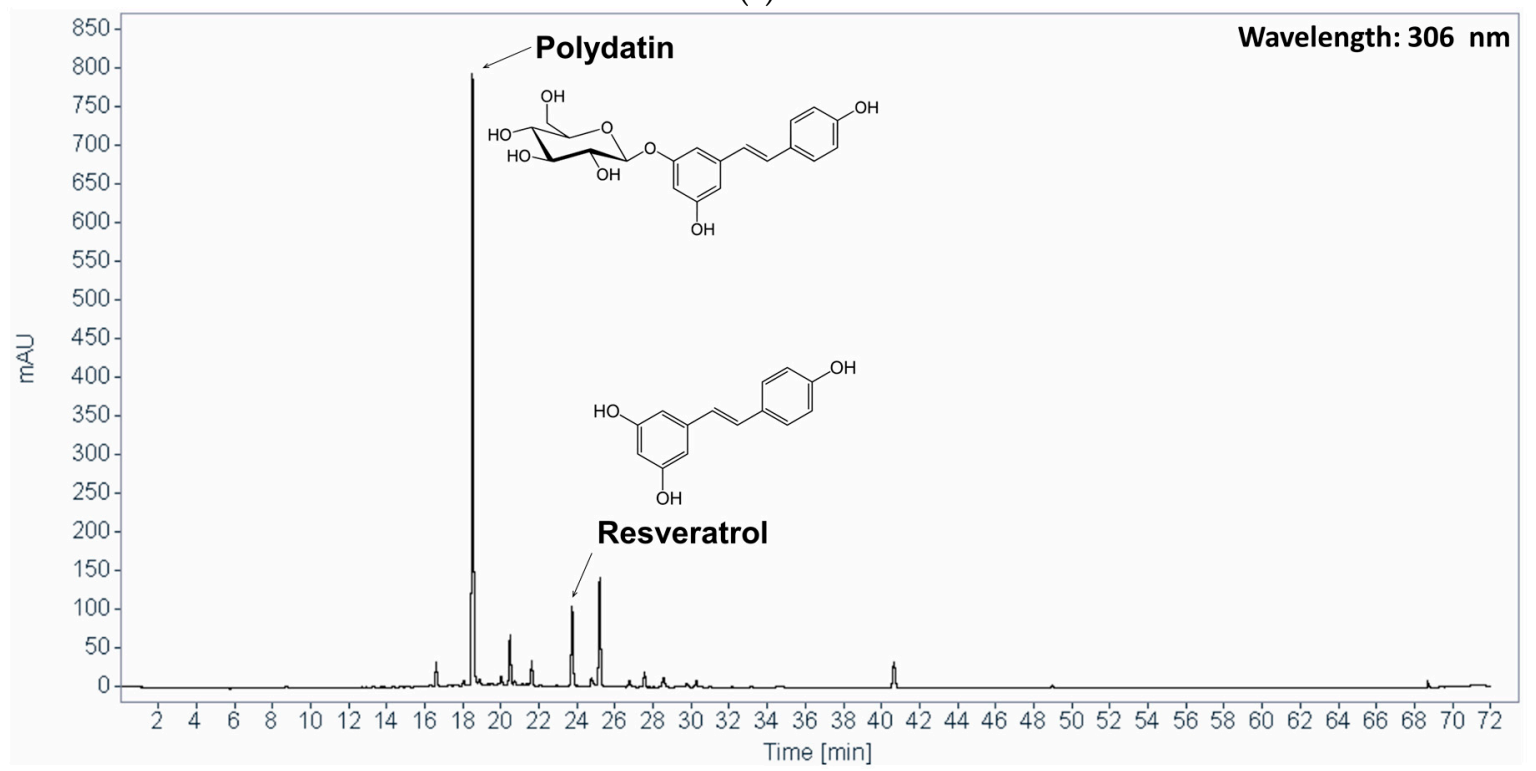

(d)

Figure 1. Chromatograms of (a) standard mixture at $290 \mathrm{~nm}$, (b) standard mixture at $306 \mathrm{~nm}$, (c) PCE at $290 \mathrm{~nm},($ d) PCE at $306 \mathrm{~nm}$. PCE, P. cuspidatum extract.

\subsection{Effect of PCE on HCl/EtOH-Induced Acute Gastric Lesions}

$\mathrm{HCl} / \mathrm{EtOH}$ administration caused severe hemorrhagic lesions that appeared as elongated bands parallel to the long axis of the glandular stomach in control rats (Figure 2a). Whereas the control group showed a lesion area of $83.3 \pm 64.0 \mathrm{~mm}^{2}$, the lesion areas of rats treated with PCE at doses of 100 and $300 \mathrm{mg} / \mathrm{kg}$ were reduced to $14 \pm 9.2 \mathrm{~mm}^{2}$ (not significant) and $1.7 \pm 2.9 \mathrm{~mm}^{2}(p<0.0001)$, respectively (Figure $2 \mathrm{~b})$. The positive control, omeprazole $(20 \mathrm{mg} / \mathrm{kg})$, also significantly reduced the lesion area to $13.5 \pm 26.7 \mathrm{~mm}^{2}(p<0.01)$. A significant decrease in gastric lesion index concomitant with the reduction in lesion area was observed for the PCE $(300 \mathrm{mg} / \mathrm{kg})$ and omeprazole treatments that were administered before $\mathrm{HCl} / \mathrm{EtOH}$ induction (Figure 2c). 
Control
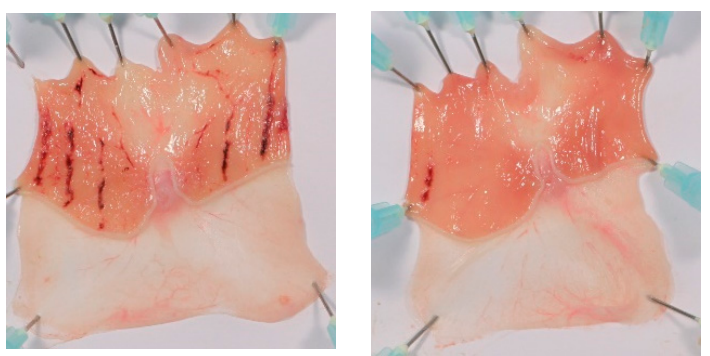

(a)
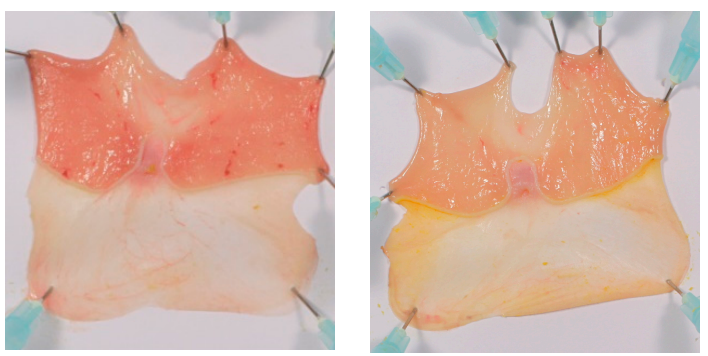

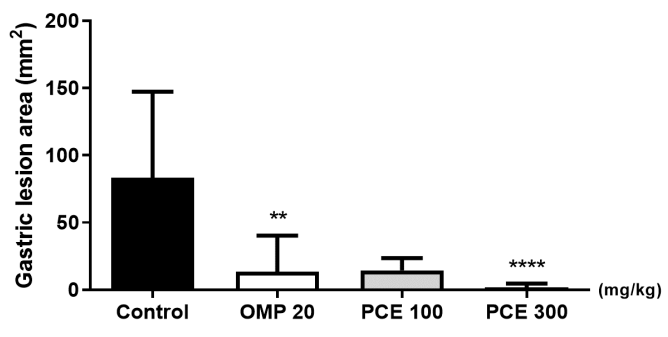

(b)

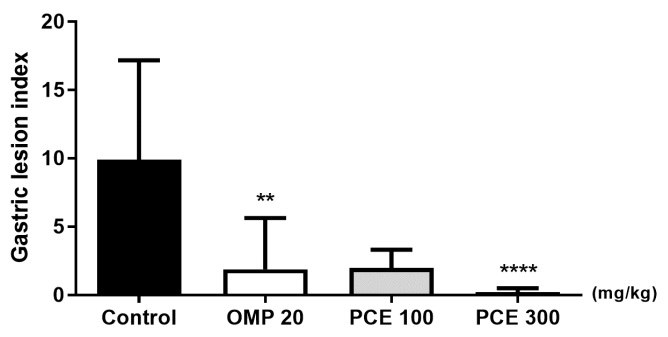

(c)

Figure 2. Effects of PCE on hydrochloric acid/ethanol $(\mathrm{HCl} / \mathrm{EtOH})$-induced rat gastric mucosal injury. (a) Representative macroscopic images of stomachs from each group. One hour prior to $\mathrm{HCl} / \mathrm{EtOH}$ administration, rats were orally treated with distilled water (control), OMP $20 \mathrm{mg} / \mathrm{kg}$, PCE $100 \mathrm{mg} / \mathrm{kg}$, or PCE $300 \mathrm{mg} / \mathrm{kg}$. Measurement of gastric lesion area (b) and gastric lesion index (c). Values are expressed as mean \pm standard deviation. $n=7-8$ per group. ${ }^{* *} p<0.01$ and ${ }^{* * * *} p<0.0001$ vs. control by Kruskal-Wallis test with Dunn's multiple comparisons test. OMP, omeprazole; PCE, P. cuspidatum extract.

\subsection{Effect of PCE on Indomethacin-Induced Acute Gastric Lesions}

Figure 3 a shows that indomethacin administration induced hemorrhagic gastric lesions in the glandular stomach. Omeprazole significantly reduced the gastric lesion area to $3.1 \pm 3.4 \mathrm{~mm}^{2}(p<0.001)$, compared to the control group, which showed a gastric lesion area of $56.8 \pm 30.9 \mathrm{~mm}^{2}$ (Figure $3 \mathrm{~b}$ ). There were no statistically significant differences in the gastric lesion area between the PCE and control groups. The gastric lesion index showed that treatment with PCE at doses of 100 and $300 \mathrm{mg} / \mathrm{kg}$ and omeprazole at $20 \mathrm{mg} / \mathrm{kg}$ significantly reduced the gastric lesion index from $6.4 \pm 2.8$ in the control group to $2.8 \pm 1.5(p<0.05), 3.3 \pm 1.5(p<0.05)$, and $0.4 \pm 0.4(p<0.01)$, respectively (Figure 3c).

\section{Control}

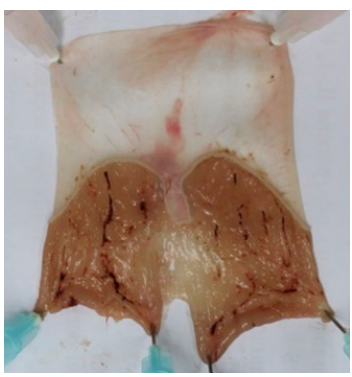

OMP 20

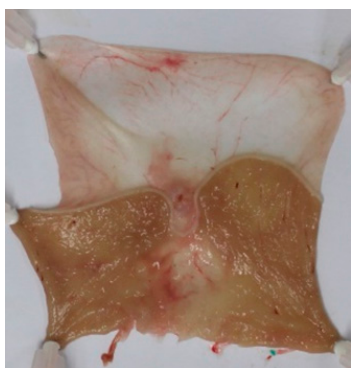

PCE 100

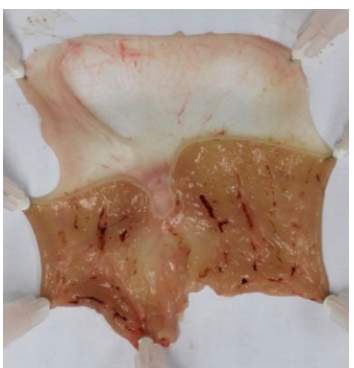

PCE 300

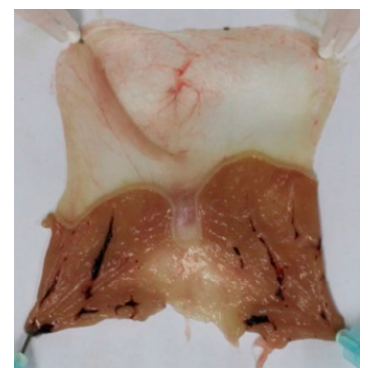

(a)

Figure 3. Cont. 


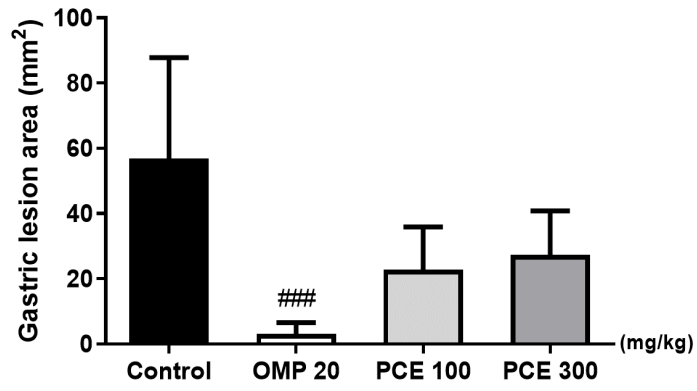

(b)

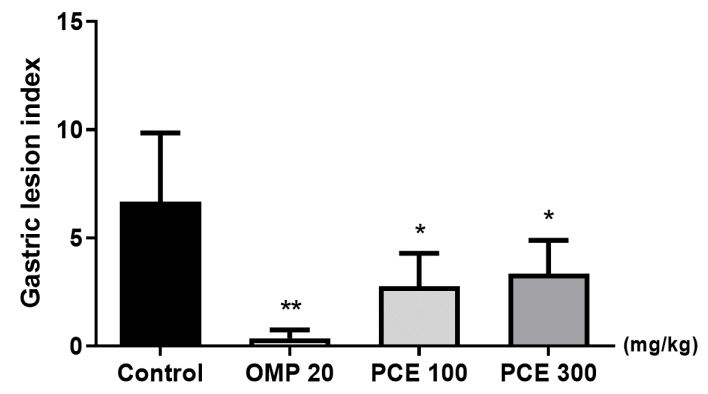

(c)

Figure 3. Gastroprotective effects of PCE on indomethacin-induced ulcer in the gastric mucosa of SD rats. (a) Representative macroscopic images of stomachs from each group. Rats were pre-treated orally with distilled water (control), OMP $20 \mathrm{mg} / \mathrm{kg}$, PCE $100 \mathrm{mg} / \mathrm{kg}$, or PCE $300 \mathrm{mg} / \mathrm{kg} 30 \mathrm{~min}$ prior to indomethacin administration. Measurement of gastric lesion area (b) and gastric lesion index (c). Values are expressed as mean \pm standard deviation. $n=6-8$ per group. ${ }^{*} p<0.05,{ }^{* *} p<0.01 \mathrm{vs}$. control by Welch's analysis of variance (ANOVA) with Dunnett's T3 multiple comparisons test, ${ }^{\# \#} p<0.001$ vs. control by Kruskal-Wallis test with Dunn's multiple comparisons test. OMP, omeprazole; PCE, P. cuspidatum extract.

\subsection{Healing Effect of PCE on Acetic Acid-Induced Chronic Gastric Ulcer}

The high dose $(300 \mathrm{mg} / \mathrm{kg})$ of PCE was selected for the acetic acid gastric ulcer model, as it was more effective than the low dose $(100 \mathrm{mg} / \mathrm{kg})$ in reducing $\mathrm{HCl} / \mathrm{EtOH}$-induced gastric lesions. The instillation of acetic acid resulted in chronic gastric ulcer in control rats, whereas the wounds of PCE-treated rats were markedly healed (Figure 4a; indicated by blue arrows). Treatment with PCE at $300 \mathrm{mg} / \mathrm{kg}$ significantly reduced the gastric lesion area $\left(30.6 \pm 5.1 \mathrm{~mm}^{2}, p<0.05\right)$ and gastric lesion index $(4.5 \pm 0.9, p<0.05)$ compared to the control group $\left(51.0 \pm 25.2 \mathrm{~mm}^{2}\right.$ and $7.6 \pm 3.9$, respectively; Figure $4 b, c)$. Omeprazole treatment did not significantly reduce gastric lesion area and index compared to the control rats.

Control

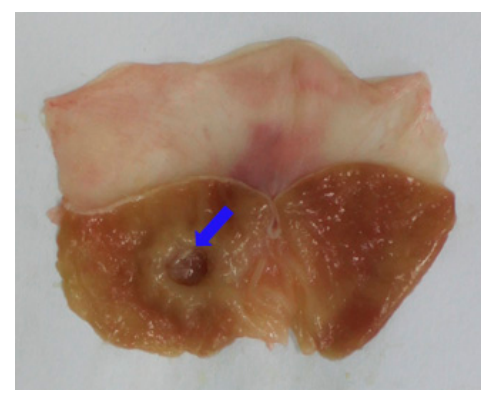

OMP 20

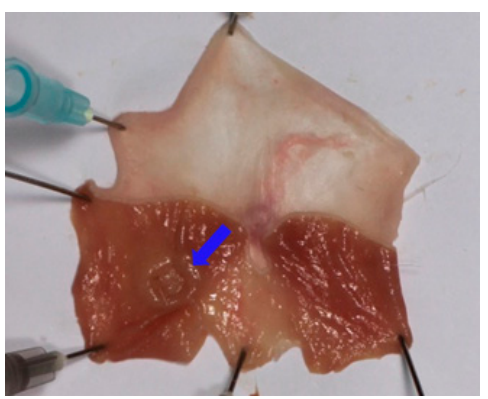

(a)
PCE 300

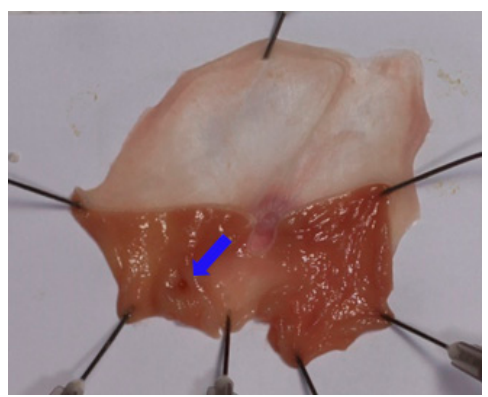

Figure 4. Cont. 


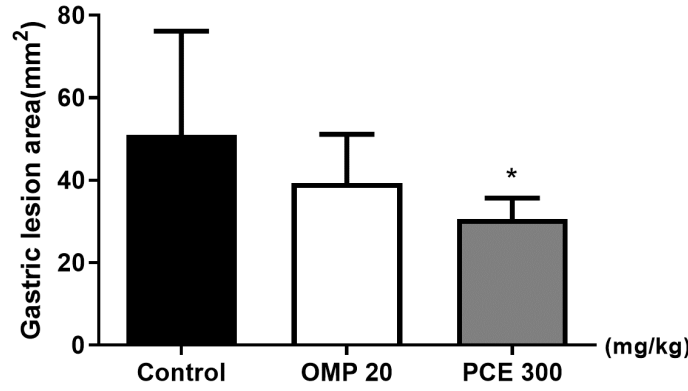

(b)

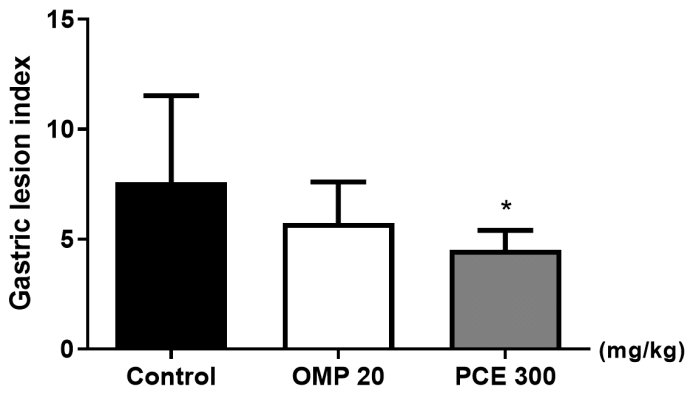

(c)

Figure 4. Healing effects of PCE on gastric ulcers induced by acetic acid. (a) Representative macroscopic images of stomachs from each group. Rats were treated orally twice a day with distilled water (control), OMP $(20 \mathrm{mg} / \mathrm{kg})$, or PCE (300 mg/kg) after surgery. Quantification of gastric lesion area (b) and gastric lesion index (c). Values are expressed as mean \pm standard deviation. $n=8-10$ per group. ${ }^{*} p<0.05$ vs. control by Kruskal-Wallis test with Dunn's multiple comparisons test. OMP, omeprazole; PCE, P. cuspidatum extract.

\subsection{Effect of PCE on Gastric Secretion}

In pylorus-ligated rats, PCE treatment did not affect the gastric secretion parameters, including volume, $\mathrm{pH}$, and acidity of gastric juice (Table 1). Omeprazole significantly increased the $\mathrm{pH}$ value and decreased free acidity compared to the control group.

Table 1. Effects of PCE on gastric secretion parameters in pylorus-ligated rats.

\begin{tabular}{ccccc}
\hline Groups & $\begin{array}{c}\text { Gastric Volume } \\
(\mathbf{m L})\end{array}$ & Gastric $\mathbf{p H}$ & $\begin{array}{c}\text { Free Acidity } \\
(\mathbf{m E q} / \mathbf{m L})\end{array}$ & $\begin{array}{c}\text { Total Acidity } \\
(\mathbf{m E q} / \mathbf{m L})\end{array}$ \\
\hline Control & $5.99 \pm 1.64$ & $1.68 \pm 0.18$ & $8.00 \pm 2.86$ & $13.72 \pm 2.31$ \\
OMP 20 mg/kg & $4.30 \pm 0.99$ & $3.07 \pm 1.42 *$ & $2.33 \pm 2.66^{\# \#}$ & $9.58 \pm 3.98$ \\
PCE 100 mg/kg & $4.52 \pm 1.85$ & $1.87 \pm 0.60$ & $7.08 \pm 3.38$ & $13.83 \pm 2.40$ \\
PCE 300 mg/kg & $6.24 \pm 1.50$ & $1.59 \pm 0.15$ & $9.40 \pm 1.95$ & $14.00 \pm 2.32$ \\
\hline
\end{tabular}

Rats were pre-treated orally with distilled water (control), OMP $20 \mathrm{mg} / \mathrm{kg}$, PCE $100 \mathrm{mg} / \mathrm{kg}$, or PCE $300 \mathrm{mg} / \mathrm{kg} 30 \mathrm{~min}$ before pylorus ligation. Gastric secretion parameters were measured $4 \mathrm{~h}$ after pylorus ligation. Values are expressed as mean \pm standard deviation. $n=5-9$ per group. ${ }^{*} p<0.05$ vs. control by Kruskal-Wallis test with Dunn's multiple comparisons test, $\#$ \# $p<0.01$ vs. control by one-way analysis of variance (ANOVA) with Dunnett's post-hoc test. OMP, omeprazole; PCE, P. cuspidatum extract.

\subsection{Effects of PCE on the Levels of SOD, GSH, and CAT in the Stomach Tissue of the HCl/EtOH-Treated Rats}

The SOD levels were significantly higher in the stomach tissue of $\mathrm{HCl} / \mathrm{EtOH}$-treated rats that had received PCE at doses of 100 and $300 \mathrm{mg} / \mathrm{kg}$ than in the control group $(p<0.01$ and $p<0.001$, respectively; Figure 5a). The GSH level was also significantly higher in the PCE $300 \mathrm{mg} / \mathrm{kg}$ group than in the control group, but CAT activity was not altered by PCE treatment (Figure 5b,c). Omeprazole significantly increased GSH level and CAT activity compared to the control group but did not change SOD level. 


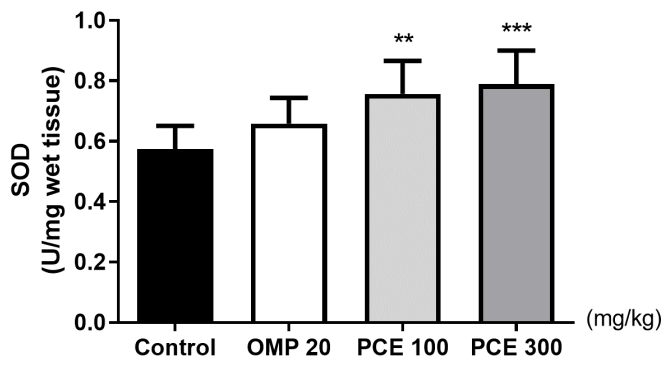

(a)

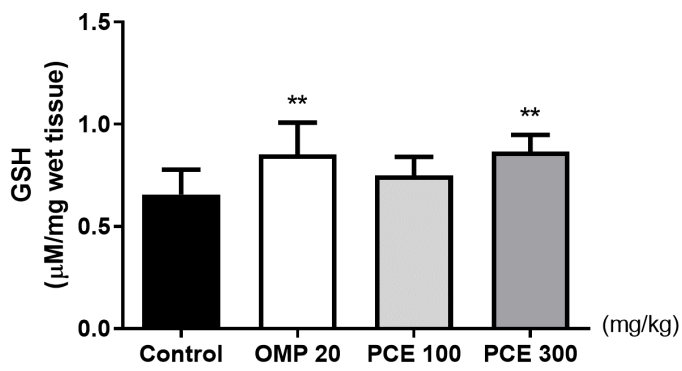

(b)

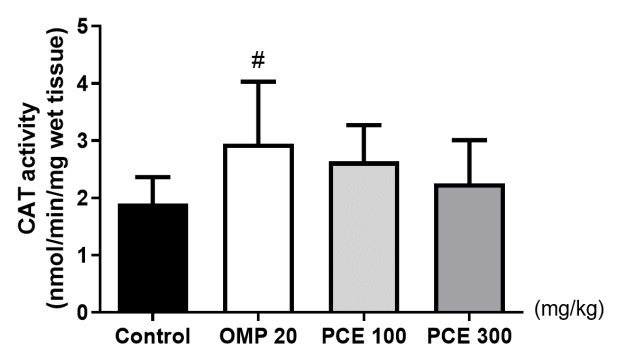

(c)

Figure 5. Effects of PCE on the levels of (a) superoxide dismutase (SOD), (b) glutathione (GSH), and (c) catalase (CAT) activity in the stomach tissue of the hydrochloric acid/ethanol $(\mathrm{HCl} / \mathrm{EtOH})$-treated rats. Rats were pre-treated orally with distilled water (control), OMP $20 \mathrm{mg} / \mathrm{kg}$, PCE $100 \mathrm{mg} / \mathrm{kg}$, or PCE $300 \mathrm{mg} / \mathrm{kg} 1 \mathrm{~h}$ prior to $\mathrm{HCl} / \mathrm{EtOH}$ administration. Values are expressed as mean \pm standard deviation. $n=7-8$ per group. ${ }^{* *} p<0.01,{ }^{* * *} p<0.001$ vs. control by one-way analysis of variance (ANOVA) with Dunnett's post-hoc test. ${ }^{\#} p<0.05$ vs. control by Kruskal-Wallis test with Dunn's multiple comparisons test. OMP, omeprazole; PCE, P. cuspidatum extract.

\subsection{Effects of PCE on the PGE 2 Level of Stomach Tissue}

The stomach tissue $\mathrm{PGE}_{2}$ level of $\mathrm{HCl} / \mathrm{EtOH}$-treated rats that received PCE at a dose of $300 \mathrm{mg} / \mathrm{kg}$ was significantly higher than that of the vehicle group $(p<0.05$, Figure 6$)$, whereas no significant difference was observed in the omeprazole group.

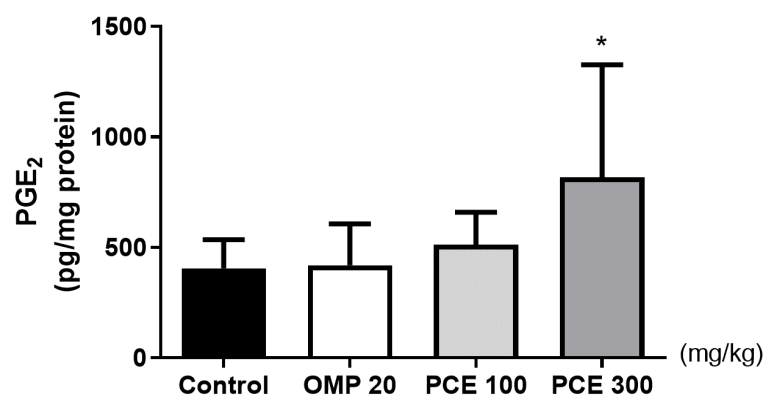

Figure 6. Effects of PCE on the levels of prostaglandin $\mathrm{E}_{2}\left(\mathrm{PGE}_{2}\right)$ in the stomach tissue of the hydrochloric acid/ethanol $(\mathrm{HCl} / \mathrm{EtOH})$-treated rats. Rats were pre-treated orally with distilled water (control), OMP $20 \mathrm{mg} / \mathrm{kg}$, PCE $100 \mathrm{mg} / \mathrm{kg}$, or PCE $300 \mathrm{mg} / \mathrm{kg} 1 \mathrm{~h}$ prior to $\mathrm{HCl} / \mathrm{EtOH}$ administration. Values are expressed as mean \pm standard deviation. $n=7-8$ per group. ${ }^{*} p<0.05$ vs. control by Kruskal-Wallis test with Dunn's multiple comparisons test. OMP, omeprazole; PCE, P. cuspidatum extract. 


\section{Discussion}

We first demonstrated that PCE pretreatment prevents acute gastric mucosal injury induced by both $\mathrm{HCl} / \mathrm{EtOH}$ and indomethacin, while PCE post-treatment promotes the healing of acetic acid-induced chronic gastric lesions. In addition, PCE increased SOD activity and GSH and PGE 2 levels in rat gastric tissue after $\mathrm{HCl} / \mathrm{EtOH}$ administration.

The gastric mucosa is the first protective layer of gastric tissue, and the mucus gel of the gastric mucosa prevents the diffusion of digestive enzymes into the stomach wall [27]. This protective layer is damaged by $\mathrm{EtOH}$, which causes erosion, ulcers, and petechial hemorrhages in the gastric mucosa by producing ROS, peroxide anions, and hydroperoxyl free radicals. Co-treatment with $\mathrm{HCl}$ evokes rapid and severe gastric injury [28]. Therefore, $\mathrm{HCl} / \mathrm{EtOH}$-induced gastric ulcers are considered a reliable tool for evaluating the efficacy of gastroprotectants. Pretreatment with PCE at doses of 100 and $300 \mathrm{mg} / \mathrm{kg}$ significantly reduced gastric lesions by $82.8 \%$ and $97.9 \%$, respectively, in rats treated with $\mathrm{HCl} / \mathrm{EtOH}$; its gastroprotective effect is comparable to that of omeprazole. These results indicate that PCE pretreatment has gastroprotective effects against acute mucosal damage caused by $\mathrm{HCl} / \mathrm{EtOH}$.

Gastric ulcers are a well-recognized complication of NSAID use. Among the widely used NSAIDs, indomethacin has the strongest ulcerogenic effect in humans and is the most commonly used ulcerogen in gastric ulcer induction [8]. Inhibition of cyclo-oxygenases (COXs) and the subsequent decrease in prostaglandin synthesis are known to be the major mechanisms contributing gastric pathogenesis induced by NSAIDs such as indomethacin [29]. In this study, pretreatment with PCE prevented indomethacin-induced acute mucosal damage in rats, suggesting that PCE exerts gastroprotective effects against NSAID-induced acute gastric ulcers.

One of the major challenges for physicians and ulcer patients is the chronic nature of gastric ulcers, which is represented by repeated cycles of healing and re-exacerbation. Experimentally induced ulcerative lesions mostly heal within a few days without scarring and do not recur spontaneously [30]. On the other hand, acetic acid causes chronic gastric ulcer because of its long-term persistence. The spontaneous recurrence of healed ulcers in this model is similar to human chronic ulcers; thus, the acetic acid model used in this study is standard for screening medicines as potential ulcer healing drugs [8,25]. The mechanisms associated with ulcer healing include increased antioxidant activity, $\mathrm{PGE}_{2}$ generation, anti-inflammation factors, inhibition of gastric acid secretion, angiogenesis, increased gastric mucus secretion, and the presence of growth factors [25,31,32]. Resveratrol, the major component of PCE, has been shown to reduce the ulcer index in acetic acid-induced gastric ulcers [22]. Our study shows that seven days of PCE treatment after ulcer induction with acetic acid reduced gastric lesions, whereas a comparable treatment regimen with omeprazole did not. This suggests that the healing effects of PCE that we observed in acetic acid-induced ulcer may be partially attributable to resveratrol.

The gastric mucosa maintains its function and structural integrity through complex, multifactorial interactions between protective factors (including mucin, prostaglandin, and antioxidants) and aggressive factors (such as gastric acid and pepsin) [33,34]. Under normal conditions, protective factors prevent local damage from continuous exposure to ulcerogens and maintain structural and functional mucosal integrity [35]. Gastric ulcers caused by EtOH are associated with mass production of ROS, which can provoke oxidative damage [36]. Antioxidants including SOD, CAT, and GSH can scavenge oxygen-derived free radicals in the gastric mucosa [37]. Depletion of cellular GSH levels, as well as reduced SOD and CAT activities, impedes recovery shortly after EtOH-induced gastric oxidative injury [38-40]. Increases in SOD, GSH, and CAT levels of the gastric tissues contribute to gastroprotection against indomethacin and to the healing of acetic acid-induced gastric mucosal injury [41-43]. Resveratrol, a main active component of P. cuspidatum, has been reported to produce gastroprotective and ulcer healing effects in EtOH- and acetic acid-induced ulcer models, respectively, by augmenting SOD, GSH, and CAT levels [21,22]. We found that the SOD activities and GSH levels were significantly higher in the gastric tissues of $\mathrm{HCl} / \mathrm{EtOH}-u$ lcerated rats. These results suggest that the gastroprotective and ulcer healing effects of PCE might be partially mediated by the antioxidant effects of resveratrol. 
Pretreatment with PCE significantly increased the $\mathrm{PGE}_{2}$ level in the gastric tissue of $\mathrm{HCl} / \mathrm{EtOH}$-ulcerated rats. Prostaglandins produced from arachidonic acid, mainly via COX-2 enzyme activity, are present throughout the gastrointestinal tract. $\mathrm{PGE}_{2}$ plays a particularly important role in gastric mucosal protection and ulcer healing by controlling gastric secretions of acid and bicarbonate, gastric blood flow, mucus production, and gastric mucosal integrity [44]. In particular, $\mathrm{PGE}_{2}$ has been reported to promote dilation and therefore blood flow of mucosal microvasculature [45]. These changes help flush free radicals from vicinity of epithelial cells and neutralize gastric acid, thus providing gastroprotection [46]. Experimental studies have shown that administration of $\mathrm{PGE}_{2}$ protects gastric mucosa against EtOH- and indomethacin-induced gastric injury and promotes healing of acetic acid-induced gastric ulcer. In addition, a previous study reported that emodin, the major component of $\mathrm{PCE}$, increases $\mathrm{PGE}_{2}$ levels in aspirin-induced acute gastric ulcer [23]. Our results, along with previous findings, indicate that an increase in $\mathrm{PGE}_{2}$ levels might contribute to the gastroprotective and ulcer healing effects of PCE and account for its antioxidant properties.

PCE treatment did not affect gastric acid secretion in pylorus-ligated rats. Since pylorus ligation causes accumulation of gastric acid and pepsin in rats, this model is used for assessing gastric secretion [47]. Acid suppressing drugs such as proton pump inhibitors and $\mathrm{H}_{2}$-receptor antagonists are not considered gastric mucosal protective agents because they rely on acid secretion inhibition [48]. Furthermore, extended inhibition of acid secretion can increase susceptibility to infection and increase the risk of gastrointestinal cancer $[48,49]$. We therefore conclude that gastric acid suppression is not likely to be a mechanism underlying the beneficial effects of PCE.

This study utilized $\mathrm{HCl} / \mathrm{EtOH}$ and indomethacin-induced rat gastric ulcer models, which are analogous to gastric mucosal damage caused by alcohol consumption and excessive NSAID use, respectively. Since $H$. pylori infection is also a major cause of gastric ulcers [7], a future study is warranted to investigate the effects of PCE in H. pylori-induced ulceration. Furthermore, because PCE treatment was associated with increased $\mathrm{PGE}_{2}$ levels in ulcerated gastric tissue, we posit that it increases mucosal microvascular blood flow. We propose to investigate the effects of PCE on microvascular blood flow in future studies.

\section{Conclusions}

In conclusion, P. cuspidatum shows gastroprotective and ulcer healing effects, which are likely associated with the antioxidant effects and the augmentation of $\mathrm{PGE}_{2}$. Based on these findings, P. cuspidatum might be a potential preventive and therapeutic agent for the treatment of gastric ulcers.

Author Contributions: Conceptualization, J.S., Y.-S.K., and H.K.; methodology, Y.-S.K. and J.S.; investigation, Y.-S.K. and Y.N.; writing-original draft preparation, Y.-S.K., Y.N., and J.S.; writing-review and editing, J.S., Y.-S.K. and H.K.; visualization, Y.-S.K. and J.S.; supervision, H.K.; project administration, H.K. All authors have read and agreed to the published version of the manuscript.

Funding: This work was supported by the Bio-Synergy Research Project (NRF-2012M3A9C4048795) of the Ministry of Science, ICT and Future Planning through the National Research Foundation.

Conflicts of Interest: The authors declare no conflict of interest.

\section{References}

1. Teschke, R.; Wolff, A.; Frenzel, C.; Eickhoff, A.; Schulze, J. Herbal traditional Chinese medicine and its evidence base in gastrointestinal disorders. World J. Gastroenterol. 2015, 21, 4466. [CrossRef] [PubMed]

2. Megala, J.; Geetha, A. Antiulcerogenic activity of hydroalcoholic fruit extract of Pithecellobium dulce in different experimental ulcer models in rats. J. Ethnopharmacol. 2012, 142, 415-421. [CrossRef] [PubMed]

3. Gururatsakul, M.; Holloway, R.H.; Talley, N.J.; Holtmann, G.J. Association between clinical manifestations of complicated and uncomplicated peptic ulcer and visceral sensory dysfunction. J. Gastroenterol. Hepatol. 2010, 25, 1162-1169. [CrossRef] [PubMed]

4. Barkun, A.; Leontiadis, G. Systematic review of the symptom burden, quality of life impairment and costs associated with peptic ulcer disease. Am. J. Med. 2010, 123, 358-366.e2. [CrossRef] 
5. Kurata, J.; Haile, B. Epidemiology of peptic ulcer disease. Clin. Gastroenterol. 1984, 13, $289-307$.

6. Kim, S.G.; Kim, J.G.; Shin, S.K.; Kim, H.S.; Seol, S.Y. Guidelines of diagnosis for peptic ulcer disease. Korean J. Gastroenterol. 2009, 54, 279-284. [CrossRef]

7. Khushtar, M.; Siddiqui, H.H.; Dixit, R.K.; Khan, M.S.; Iqbal, D.; Rahman, M.A. Amelioration of gastric ulcers using a hydro-alcoholic extract of Triphala in indomethacin-induced Wistar rats. Eur. J. Integr. Med. 2016, 8, 546-551. [CrossRef]

8. Adinortey, M.B.; Ansah, C.; Galyuon, I.; Nyarko, A. In vivo models used for evaluation of potential antigastroduodenal ulcer agents. Ulcers 2013, 2013, 1-12. [CrossRef]

9. Okabe, S.; Pfeiffer, C.J. Chronicity of acetic acid ulcer in the rat stomach. Am. J. Dig. Dis. 1972, 17, 619-629. [CrossRef]

10. Penston, J.G. A decade of experience with long-term continuous treatment of peptic ulcers with $\mathrm{H}_{2}$-receptor antagonists. Aliment. Pharmacol. Ther. 1993, 7, 27-33. [CrossRef]

11. Boeing, T.; da Silva, L.M.; Somensi, L.B.; Cury, B.J.; Costa, A.P.M.; Petreanu, M.; Niero, R.; de Andrade, S.F. Antiulcer mechanisms of Vernonia condensata Baker: A medicinal plant used in the treatment of gastritis and gastric ulcer. J. Ethnopharmacol. 2016, 184, 196-207. [CrossRef] [PubMed]

12. Chey, W.D.; Leontiadis, G.I.; Howden, C.W.; Moss, S.F. ACG Clinical guideline: Treatment of Helicobacter pylori infection. Am. J. Gastroenterol. 2017, 112, 212-239. [CrossRef] [PubMed]

13. Lee, S.H.; Lee, D.J.; Kim, K.M.; Park, S.B.; Kim, B.T.; Joo, N.S.; Cho, D.Y.; Kim, K.N.; Seo, S.W.; Park, S.E.; et al. Diagnosis and management of peptic ulcer disease. Korean J. Fam. Pract. 2013, 3, 395-405.

14. Peng, W.; Qin, R.; Li, X.; Zhou, H. Botany, phytochemistry, pharmacology, and potential application of Polygonum cuspidatum Sieb.et Zucc.: A review. J. Ethnopharmacol. 2013, 148, 729-745. [CrossRef] [PubMed]

15. Zhao, Y.; Chen, M.X.; Kongstad, K.T.; Jäger, A.K.; Staerk, D. Potential of Polygonum cuspidatum root as an antidiabetic food: Dual high-resolution $\alpha$-glucosidase and PTP1B inhibition profiling combined with HPLC-HRMS and NMR for identification of antidiabetic constituents. J. Agric. Food Chem. 2017, 65, 4421-4427. [CrossRef] [PubMed]

16. Kim, D.; Kim, H.; Ko, H. Endothelium dependent vasorelaxant effect of aqueous extract of Polygoni cuspidatae radix on arterial contraction in rabbit. Korean J. Orient. Physiol. Pathol. 2008, 22, 131-136.

17. Sohn, E.; Kim, J.; Kim, C.S.; Lee, Y.M.; Kim, J.S. Extract of Polygonum cuspidatum attenuates diabetic retinopathy by inhibiting the high-mobility group box-1 (HMGB1) signaling pathway in streptozotocin-induced diabetic rats. Nutrients 2016, 8, 140. [CrossRef]

18. Ding, X.P.; Zhang, C.L.; Qi, J.; Sun, L.Q.; Qin, M.J.; Yu, B.Y. The Spectrum-Effect integrated fingerprint of Polygonum cuspidatum based on HPLC-diode array detection-flow injection-chemiluminescence. Chin. J. Nat. Med. 2013, 11, 546-552. [CrossRef]

19. Park, B.; Lee, I.S.; Hyun, S.W.; Jo, K.; Lee, T.G.; Kim, J.S.; Kim, C.S. The protective effect of polygonum cuspidatum (PCE) aqueous extract in a dry eye model. Nutrients 2018, 10, 1550. [CrossRef]

20. Park, B.; Jo, K.; Lee, T.G.; Hyun, S.W.; Kim, J.S.; Kim, C.S. Polydatin inhibits NLRP3 inflammasome in dry eye disease by attenuating oxidative stress and inhibiting the NF-kB pathway. Nutrients 2019, 11, 2792. [CrossRef]

21. Hussein, S.A.; Karousa, M.M.; Amin, A.; Awadalla, M.A. Evaluation of gastroprotective effect and anti-inflammatory role of resveratrol against gastric mucosal alterations in experimental model of gastritis in rats. Int. J. Pharma Sci. 2016, 6, 1559-1570.

22. Solmaz, A.; Şener, G.; Çetinel, Ş.; Yüksel, M.; Yeğen, C.; Yeğen, B.Ç. Protective and therapeutic effects of resveratrol on acetic acid-induced gastric ulcer. Free Radic. Res. 2009, 43, 594-603. [CrossRef] [PubMed]

23. Mishra, V. Potent gastroprotective effect chrysophanol and emodin from Rehum Emodi via $\mathrm{H}^{+} \mathrm{K}^{+}$atpase inhibition and increasing the $\mathrm{PGE}_{2}$ Level in rats. Nat. Prod. Indian J. 2016, 12, 1-12.

24. Mizui, T.; Doteuchi, M. Effect of polyamines on acidified ethanol-induced gastric lesions in rats. Jpn. J. Pharmacol. 1983, 33, 939-945. [CrossRef]

25. Okabe, S.; Amagase, K. An overview of acetic acid ulcer models-The history and state of the art of peptic ulcer research. Biol. Pharm. Bull. 2005, 28, 1321-1341. [CrossRef] [PubMed]

26. Shay, H.; Gruenstein, M. A simple and safe method for the gastric instillation of fluids in the rat. J. Lab. Clin. Med. 1946, 31, 1384-1386. 
27. Saremi, K.; Rad, S.K.; Tayeby, F.; Abdulla, M.A.; Karimian, H.; Majid, N.A. Gastroprotective activity of a novel schiff base derived dibromo substituted compound against ethanol-induced acute gastric lesions in rats. BMC Pharmacol. Toxicol. 2019, 20, 13. [CrossRef]

28. Marhuenda, E.; Martin, M.J.; Lastra, C.D. Antiulcerogenic activity of aescine in different experimental models. Phytother. Res. 1993, 7, 13-16. [CrossRef]

29. Takeuchi, K. Pathogenesis of NSAID-induced gastric damage: Importance of cyclooxygenase inhibition and gastric hypermotility. World J. Gastroenterol. 2012, 18, 2147. [CrossRef]

30. Takagi, K.; Okabe, S.; Saziki, R. A new method for the production of chronic gastric ulcer in rats and the effect of several drugs on its healing. Jpn. J. Pharmacol. 1969, 19, 418-426. [CrossRef]

31. Banerjee, D.; Maity, B.; Nag, S.K.; Bandyopadhyay, S.K.; Chattopadhyay, S. Healing potential of Picrorhiza kurroa (Scrofulariaceae) rhizomes against indomethacin-induced gastric ulceration: A mechanistic exploration. BMC Complementary Altern. Med. 2008, 8, 3. [CrossRef] [PubMed]

32. Konturek, S.; Konturek, P.; Brzozowski, T. Prostaglandins and ulcer healing. J. Physiol. Pharmacol. $2005,56,5$. [PubMed]

33. Baiubon, P.; Kunanusorn, P.; Khonsung, P.; Chiranthanut, N.; Panthong, A.; Rujjanawate, C. Gastroprotective activity of the rhizome ethanol extract of Zingiber simaoense YY Qian in rats. J. Ethnopharmacol. 2016, 194, 571-576. [CrossRef] [PubMed]

34. Eastwood, G.L. Is smoking still important in the pathogenesis of peptic ulcer disease? J. Clin. Gastroenterol. 1997, 25, S1-S7. [CrossRef] [PubMed]

35. Laine, L.; Takeuchi, K.; Tarnawski, A. Gastric mucosal defense and cytoprotection: Bench to bedside. Gastroenterology 2008, 135, 41-60. [CrossRef]

36. Rezaie, A.; Parker, R.D.; Abdollahi, M. Oxidative stress and pathogenesis of inflammatory bowel disease: An epiphenomenon or the cause? Dig. Dis. Sci. 2007, 52, 2015-2021. [CrossRef]

37. Wu, X.; Huang, Q.; Xu, N.; Cai, J.; Luo, D.; Zhang, Q.; Su, Z.; Gao, C.; Liu, Y. Antioxidative and anti-inflammatory effects of water extract of Acrostichum aureum Linn. against ethanol-induced gastric ulcer in rats. Evid. Based Complementary Altern. Med. 2018, 2018, 1-10. [CrossRef]

38. Song, S.H.; Kim, J.E.; Sung, J.E.; Lee, H.A.; Yun, W.B.; Lee, Y.H.; Song, H.; Hwang, D. Anti-ulcer effect of Gallarhois extract with anti-oxidant activity in an ICR model of ethanol/hydrochloride acid-induced gastric injury. J. Tradit. Complementary Med. 2019, 9, 372-382. [CrossRef]

39. Zhou, D.; Yang, Q.; Tian, T.; Chang, Y.; Li, Y.; Duan, L.R.; Li, H.; Wang, S.W. Gastroprotective effect of gallic acid against ethanol-induced gastric ulcer in rats: Involvement of the Nrf2/HO-1 signaling and anti-apoptosis role. Biomed. Pharmacother. 2020, 126, 110075. [CrossRef]

40. Szabo, S.; Trier, J.S.; Frankel, P.W. Sulfhydryl compounds may mediate gastric cytoprotection. Science 1981, 214, 200-202. [CrossRef]

41. Zaghlool, S.S.; Abo-Seif, A.A.; Rabeh, M.A.; Abdelmohsen, U.R.; Messiha, B.A. Gastro-protective and anti-oxidant potential of Althaea officinalis and Solanum nigrum on pyloric ligation/indomethacin-induced ulceration in rats. Antioxidants 2019, 8, 512. [CrossRef] [PubMed]

42. Antonisamy, P.; Arasu, M.V.; Dhanasekaran, M.; Choi, K.C.; Aravinthan, A.; Kim, N.S.; Kang, C.W.; Kim, J.H. Protective effects of trigonelline against indomethacin-induced gastric ulcer in rats and potential underlying mechanisms. Food Funct. 2016, 7, 398-408. [CrossRef] [PubMed]

43. Mei, X.T.; Xu, D.H.; Xu, S.K.; Zheng, Y.P.; Xu, S.B. Zinc (II)-curcumin accelerates the healing of acetic acid-induced chronic gastric ulcers in rats by decreasing oxidative stress and downregulation of matrix metalloproteinase-9. Food Chem. Toxicol. 2013, 60, 448-454. [CrossRef]

44. Perico, L.L.; Heredia-Vieira, S.C.; Beserra, F.P.; de Cassia Dos Santos, R.; Weiss, M.B.; Resende, F.A.; Dos Santos Ramos, M.A.; Bonifacio, B.V.; Bauab, T.M.; Varanda, E.A.; et al. Does the gastroprotective action of a medicinal plant ensure healing effects? An integrative study of the biological effects of Serjania marginata Casar. (Sapindaceae) in rats. J. Ethnopharmacol. 2015, 172, 312-324. [CrossRef] [PubMed]

45. Malfertheiner, P.; Chan, F.K.; McColl, K.E. Peptic ulcer disease. The lancet 2009, 374, 1449-1461. [CrossRef]

46. Uzal, F.A.; Plattner, B.L.; Hostetter, J.M. Alimentary system. In Jubb, Kennedy and Palmer's Pathology of Domestic Animals, 6th ed.; Maxie, M.G., Ed.; Elsevier: St. Louis, MO, USA, 2016; Volume 2, p. 46.

47. Jaikumar, S.; Ramaswamy, S.; Asokan, B.R.; Mohan, T.; Gnanavel, M. Anti ulcer activity of methanolic extract of Jatropha curcas (Linn.) on Aspirin-induced gastric lesions in Wistar strain rats. Res. J. Pharm. Biol. Chem. Sci. 2010, 1, 886-897. 
48. D'Argenio, G.; Mazzone, G.; Tuccillo, C.; Grandone, I.; Gravina, A.G.; Graziani, G.; Fogliano, V.; Romano, M. Apple polyphenol extracts prevent aspirin-induced damage to the rat gastric mucosa. Br. J. Nutr. 2008, 100, 1228-1236. [CrossRef]

49. Rodriguez, L.G.; Lagergren, J.; Lindblad, M. Gastric acid suppression and risk of oesophageal and gastric adenocarcinoma: A nested case control study in the UK. Gut 2006, 55, 1538-1544. [CrossRef]

(C) 2020 by the authors. Licensee MDPI, Basel, Switzerland. This article is an open access article distributed under the terms and conditions of the Creative Commons Attribution (CC BY) license (http://creativecommons.org/licenses/by/4.0/). 